\title{
Acute skeletal myopathy in farmed Atlantic salmon Salmo salar
}

\author{
H. D. Rodger ${ }^{1}$, T. M. Murphy ${ }^{1}$, E. M. Drinan ${ }^{1}$, D. A. Rice $^{2}$ \\ ${ }^{1}$ National Diagnostics Centre, BioResearch Ireland, University College, Galway, Ireland \\ ${ }^{2}$ Nutrition Services (Int.), Ltd, Randalstown, Co. Antrim, Northern Ireland
}

\begin{abstract}
This paper describes the clinical findings, histopathology and biochemistry of a significant disease affecting marine stage Atlantic salmon in Ireland, known as 'sudden death syndrome'. Pathological findings were located predominantly in the skeletal muscle and affected farms all had a history of pancreas disease. The skeletal myopathy was severe and degenerative in appearance with red muscle bundle necrosis and degeneration most obvious. Blood biochemistry confirmed the severe myopathy through significantly elevated creatine kinase levels. It is proposed that the myopathy has its basis in nutritional deficiency and exertional stress, brought about through an outbreak of pancreas disease.
\end{abstract}

\section{INTRODUCTION}

In recent years in Ireland, there has been an increased incidence of a disease syndrome known colloquially as 'sudden death syndrome' (SDS), which affects marine stage farmed Atlantic salmon Salmo salar in their first year at sea. It has resulted in such significant mortalities that some farmers have been forced to move farm sites or cease production.

All stocks examined and affected by SDS have a history of pancreas disease (PD) (Munro et al. 1984) at some time prior to the outbreak of SDS; the majority of farms report a decrease in feeding response and on examination of fish by standard histological methods pathology of the pancreatic exocrine tissue can be confirmed, consistent with that described as PD. Other than the varying decrease in feeding response no other problems are usually encountered during this period. However on return to normal feeding, which can take from 3 to $8 \mathrm{wk}$, some cages and sites start to experience significant mortalities in the externally best condition fish. The return to feeding is often reported as being aggressive and vigorous. Concomitant with this behaviour is the dramatic rise in mortalities. There are usually very few moribund fish although occasional circling fish can be seen on the cage surface, which appear externally in good condition. Similar moribund, circling fish are also reported by divers at the bottom of the cages. On some farms thin, dark, anorexic fish with clinical symptoms of PD are present on the water surface. In Ireland the majority of sites that experience pancreas disease do not experience SDS, but within the last 2 yr there has been an increased incidence of this syndrome.

This paper reports findings from 2 marine sites which experienced this disorder in 1990 and compares them to 2 unaffected sites. The underlying aetiology is also examined.

\section{MATERIALS AND METHODS}

Fish. A total of 135 post-smolts were sampled from the 2 affected sites (Sites $A$ and $B$ ) during the period of mortalities (October to November 1990). Three population groups from each cage were collected; moribund, good condition fish sampled by a diver from the cage floor (Group 1), thin, poor condition fish sampled from the cage surface (Group 2) and apparently healthy feeding fish sampled while at feeding (Group 3). A total of 24 apparently healthy post-smolts were sampled from 2 sites unaffected by SDS (Sites C and D), one of which (Site C) had PD confirmed 2 mo prior to sampling. The population groups and sites are summarised in Table 1. The origin of these fish was a mixture of Norwegian/Irish and Scottish strains and all were reared at a variety of fresh water sites in Ireland. The weight of the sampled fish ranged from 250 to $800 \mathrm{~g}$. 
Fish at all 4 sites were fed commercially pelleted feed from a number of different feed compounders. All 4 sites were situated in coastal waters in Co. Galway, Ireland.

Histology. Fish were sampled from the following organs for histology; gills, pyloric caeca and pancreas, heart, brain, liver, oesophagus, kidney and spleen. Skin and muscle sections were also taken from 4 different parts of the body: (1) the cephalic portion of the adductor mandibularis and the dilator operculi, both superficial muscles of the head; (2) the pectoral abductor and adductors; (3) medial trunk including the lateral line; and (4) at the caudal peduncle, including the dorsal and ventral caudal flexor muscles. These were all fixed in $10 \%$ phosphate-buffered formalin, processed routinely, sectioned $(5 \mu \mathrm{m})$ and stained with haematoxylin and eosin ( $\mathrm{H} \& \mathrm{E}$ ).

Bacteriology. Kidney swabs were taken from fish from the affected farms, plated out on Brain Heart Infusion Agar (Oxoid), Brain Heart infusion Agar plus $1.5 \%$ salt $(\mathrm{NaCl})$ and Marine Agar (Difco) and incubated at $20^{\circ} \mathrm{C}$ for a minimum of $2 \mathrm{wk}$. Additionally, for fish from one site (Site B), samples were plated on Selective Kidney Disease Medium (SKDM) at $15^{\circ} \mathrm{C}$ for 12 wk as described by Austin et al. (1983).

Virology. Kidney and spleen tissue samples were taken from the 2 affected farms, pooled in lots of 5 and processed routinely at the Fisheries Research Centre,
Table 1. Salmo salar. Description of sample populations. + High SDS mortalities; \pm : some SDS mortalities; - no SDS mortalities

\begin{tabular}{|c|c|c|c|}
\hline Site & Group & Description of fish & SDS \\
\hline \multirow[t]{3}{*}{$\mathrm{A}$} & 1 & $\begin{array}{l}\text { Good condition, } \\
\text { moribund }\end{array}$ & + \\
\hline & 2 & $\begin{array}{l}\text { Poor condition, } \\
\text { moribund }\end{array}$ & - \\
\hline & 3 & $\begin{array}{l}\text { Good condition, } \\
\text { feeding }\end{array}$ & \pm \\
\hline \multirow[t]{3}{*}{$B$} & 1 & $\begin{array}{l}\text { Good condition, } \\
\text { moribund }\end{array}$ & + \\
\hline & 2 & $\begin{array}{l}\text { Poor condition, } \\
\text { moribund }\end{array}$ & - \\
\hline & 3 & $\begin{array}{l}\text { Good condition, } \\
\text { feeding }\end{array}$ & \pm \\
\hline C & All & $\begin{array}{l}\text { Good condition, } \\
\text { seeding }\end{array}$ & - \\
\hline $\mathrm{D}$ & All & $\begin{array}{l}\text { Good condition, } \\
\text { feeding }\end{array}$ & - \\
\hline
\end{tabular}

Dublin and the Institute of Aquaculture, Stirling, Scotland.

Biochemistry and haematology. Fish were quickly netted out of the cages, immediately euthanased by a blow to the head and heparinised blood samples taken from the caudal vein. All blood samples were held at 0 to

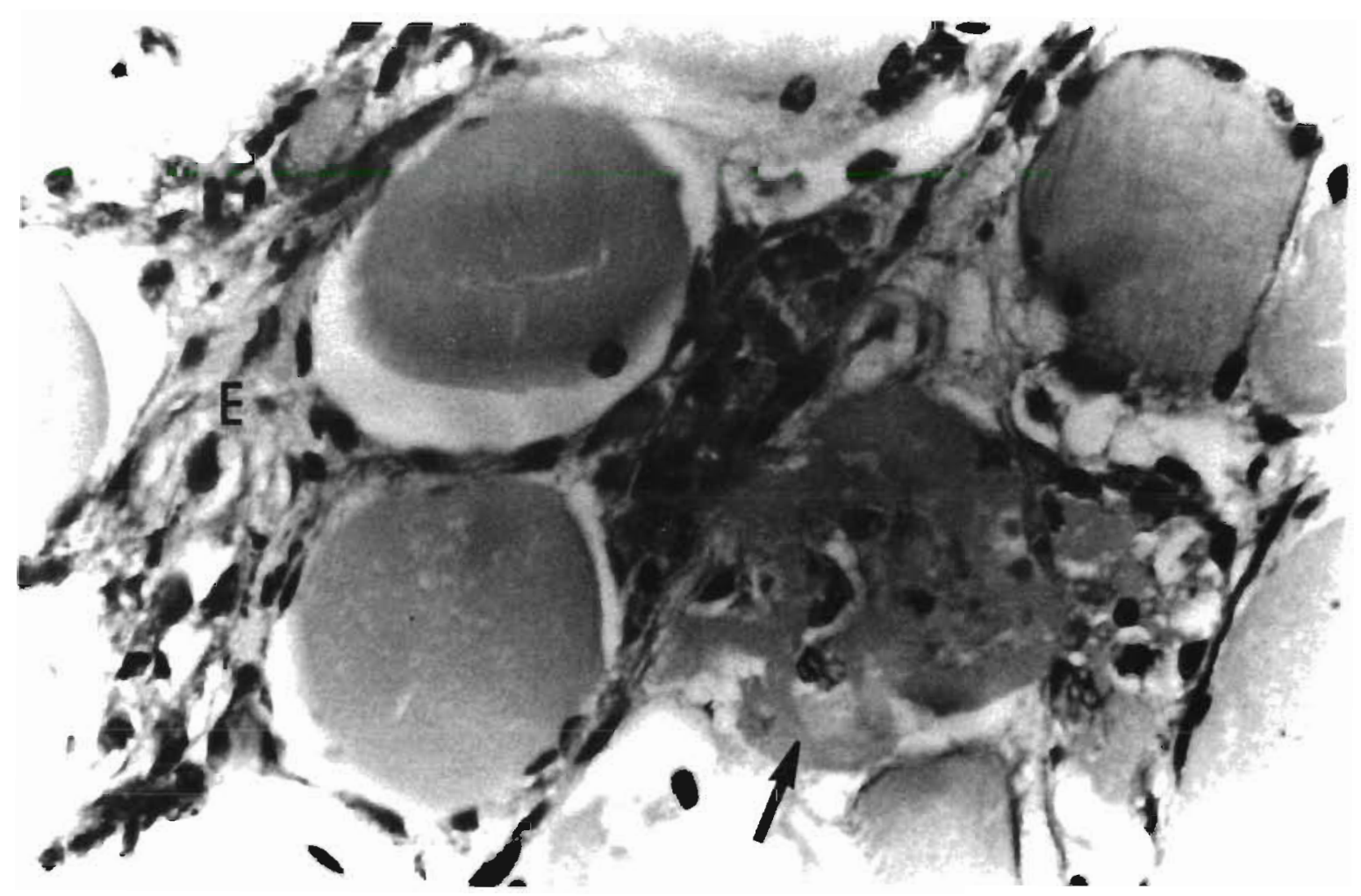

Fig. 1. Salmo salar. Skeletal muscle of Atlantic salmon showing fibre disruption and phagocytosis of debris by macrophages Arrow: degenerating muscle bundles; $E$ : increased endomysial connective tissue $(\mathrm{H} \& \mathrm{E}, \times 1000)$ 
$4{ }^{\circ} \mathrm{C}$ until analysis, which was completed within $24 \mathrm{~h}$ of sampling. Haematocrits were established by centrifuging samples in heparinised capillary tubes at $11000 \times g$ for $10 \mathrm{~min}$. Plasma creatine kinase (CK) assays were performed using commercial clinical chemistry kits (Ciba Corning). Blood lactate levels were established using clinical chemistry kits (Boehringer). Liver samples were stored at $-20^{\circ} \mathrm{C}$ until analysed for vitamin E levels as described by McMurray et al. (1980).

Results were examined for statistical differences between populations using a Student's t-test.

\section{RESULTS}

\section{Histology}

All 3 groups of fish in the 2 SDS-affected sites (Sites $A$ and $B$ ) had myodegeneration of the skeletal muscle with widespread bundle necrosis. Centralisation of nucleii in muscle fibres and phagocytosis of muscle debris by macrophages were often observed (Fig. 1). An increase in endomysial connective tissue was also obvious. Regenerative activity was seen as proliferation of the sarcolemmal cells giving an appearance of hypercellularity (Fig. 2). The possibility of a polymyositis was considered, but inflammatory cells were only an occasional finding and then in the endomysial tissue outside the muscle fibres.

The muscle groups affected varied considerably from fish to fish; the pectoral adductors and the abductors presented severe pathology compared to the trunk/ lateral line block in some fish and vice versa in others. Although both red and white muscle were affected the most severe pathology was seen predominantly in the red muscle areas, in particular the block running below the lateral line. In a limited number of fish from which bilateral muscle samples were taken, lesions were present in both sides of the body. In general the muscle changes were clearly more degenerative than inflammatory in nature.

Cardiac muscle changes were observed in both the atria and the ventricles of affected fish. The changes most frequently observed were focal areas of myodegeneration in the trabeculae of the ventricles. These foci showed necrosis and a proliferation of the endocardial cells. Similar changes were also seen in the compact layers of the ventricles and occasionally affecting the epicardium

None of the fish sampled from the unaffected sites (Sites C and D) showed the skeletal muscle pathology although $2 / 12$ and $4 / 12$ fish from Sites $C$ and $D$ respectively presented cardiac pathology (Figs. $3 \& 4$ ). The sample groups with the highest levels of cardiac

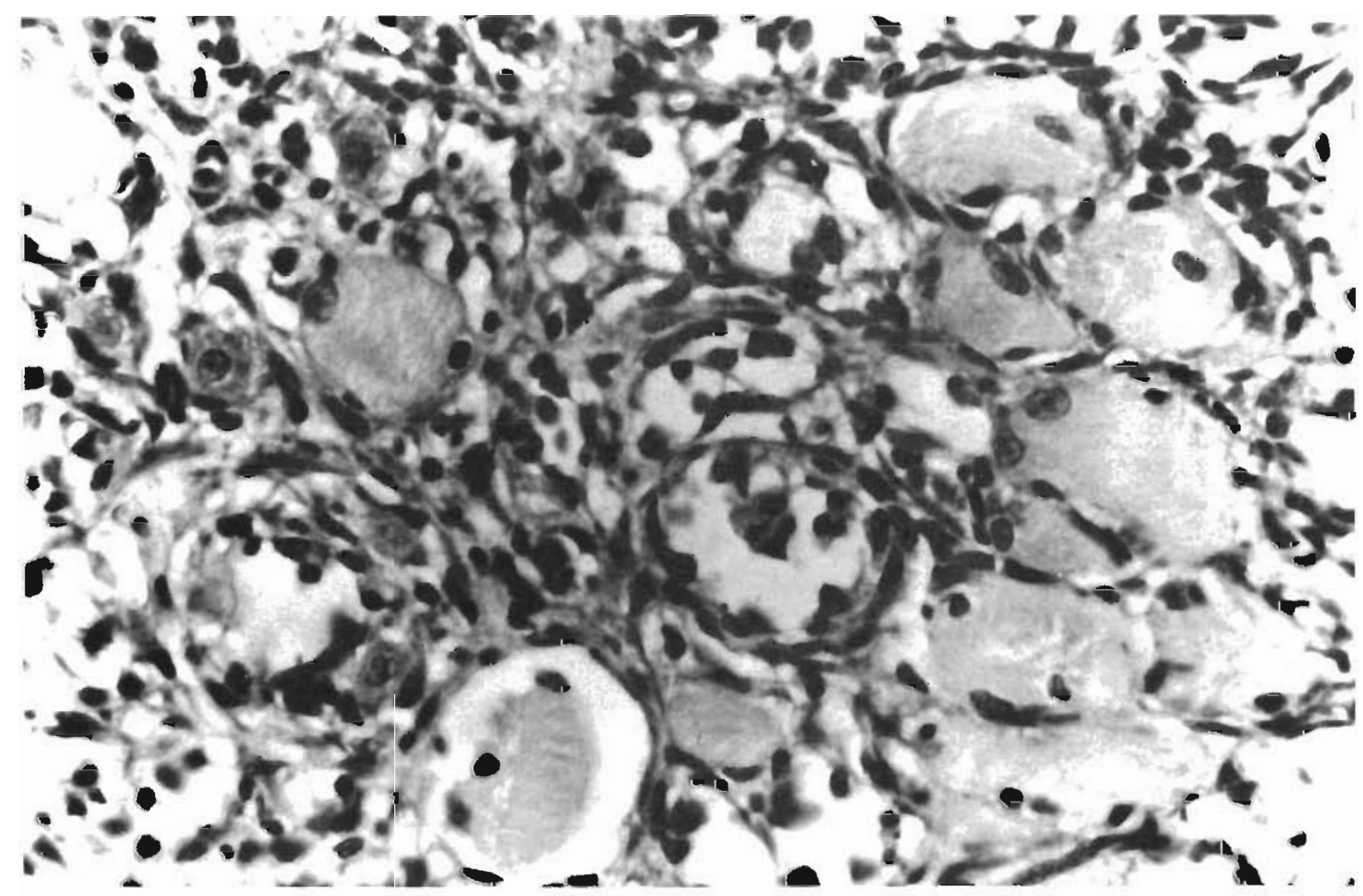

Fig. 2. Salmo salar. Section through red muscle of Atlantic salmon showing fibre degeneration, increase in endomysial connective tissue and proliferation of sarcolemmal cells giving an appearance of hypercellularity ( $\left.\mathrm{H} \& \mathrm{E}_{1} \times 400\right)$ 
pathology were Groups $\mathrm{A} 2$ and B2, the poor condition, surface fish, i.e. those which were not experiencing high mortalities at the time of sampling. In all affected sites the good condition fish, both moribund and apparently healthy, had the greatest level of skeletal muscle pathology.

Absence of the exocrine acinar pancreatic tissue and extensive fibrosis in the pancreatic region was observed in fish from Sites A, B and C. There was no evidence of this pancreas disease in the fish sampled from Site D (Fig. 5).

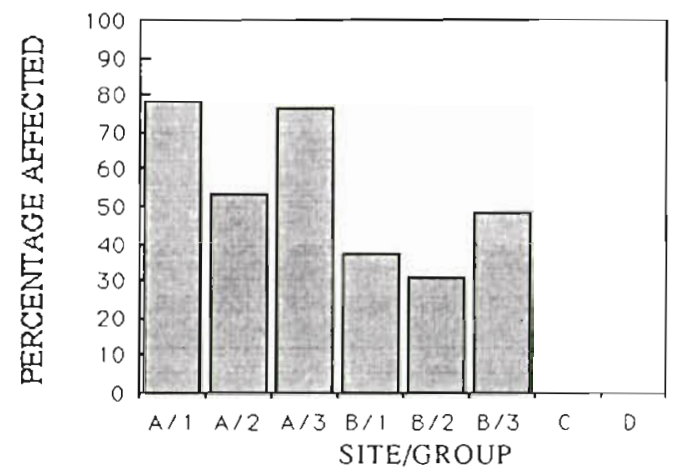

Fig. 3. Salmo salar. Percentage of samples with skeletal myopathy

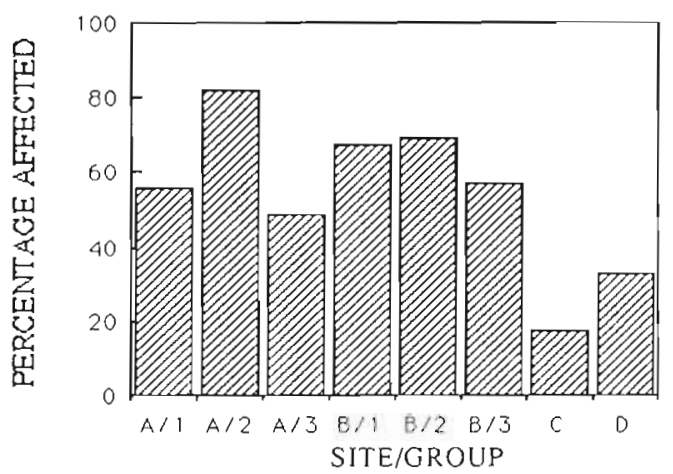

Fig. 4. Salmo salar. Percentage of samples with cardiac pathology

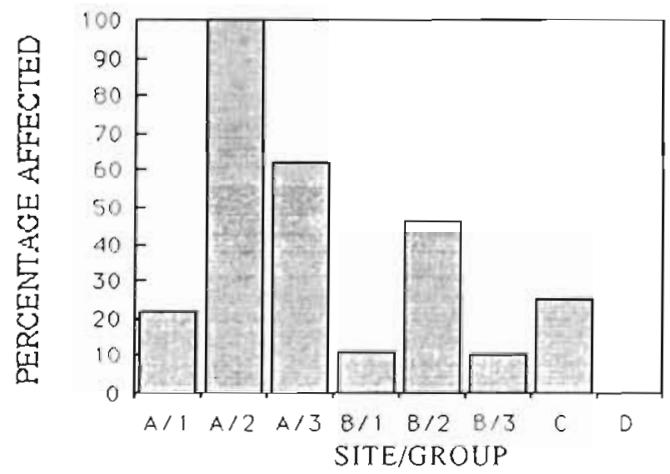

Fig. 5. Salmo salar. Percentage of samples with pancreas disease
Myodegeneration similar to the skeletal muscle changes were also an occasional finding in the circular muscle in the oesophagus and were observed in all groups of fish from Sites A and B. Focal areas of hepatic cell necrosis were also observed in some moribund fish from Sites A and B.

\section{Bacteriology and virology}

All bacterial and virological examinations proved negative for the presence of pathogenic organisms with standard isolation procedures.

\section{Biochemistry and haematology}

The results of the blood and liver analyses are shown in Table 2. Plasma creatine kinase levels were significantly raised ( $p<0.01$ to 0.001 ) for all groups at Site A and $B$ when compared to mean levels in samples from the unaffected sites. It should be taken into account that, during plasma creatine kinase analysis, in cases where levels were greater than $30000 \mathrm{IU} \mathrm{l}^{-1}$, no further titrations were made, resulting in mean values for those

Table 2. Salmo salar. Analysis of blood and liver samples from Atlantic salmon. Below values are (SD) and number of fish sampled

\begin{tabular}{|c|c|c|c|c|}
\hline $\begin{array}{l}\text { Site/ } \\
\text { group }\end{array}$ & $\begin{array}{c}\text { Plasma CK } \\
\left(\mathrm{IU} \mathrm{I}^{-1}\right)\end{array}$ & $\begin{array}{l}\text { Lactate } \\
\left(\mathrm{mmol} \mathrm{l^{-1 }}\right)\end{array}$ & $\begin{array}{c}\text { Haemocrit } \\
(\%)\end{array}$ & $\begin{array}{l}\text { Liver vit. E } \\
\left(\mu g g^{-1}\right)\end{array}$ \\
\hline $\mathrm{A} / 1$ & $\begin{array}{l}16238 \\
(9603) \\
9\end{array}$ & $\begin{array}{l}22.9 \\
(8.6) \\
8\end{array}$ & $\begin{array}{l}36.2 \\
(6.0) \\
9\end{array}$ & $\begin{array}{l}380.5 \\
(112.8) \\
6\end{array}$ \\
\hline $\mathrm{A} / 2$ & $\begin{array}{l}11889 \\
(8169) \\
15\end{array}$ & $\begin{array}{l}8.8 \\
(2.6) \\
12\end{array}$ & $\begin{array}{l}30.6 \\
(7.7) \\
15\end{array}$ & $\begin{array}{l}201.9 \\
(165.7) \\
10\end{array}$ \\
\hline $\mathrm{A} / 3$ & $\begin{array}{l}10732 \\
(4181) \\
25\end{array}$ & $\begin{array}{l}14.3 \\
(3.9) \\
10\end{array}$ & $\begin{array}{l}38.1 \\
(7.1) \\
25\end{array}$ & $\begin{array}{l}298.0 \\
(159.0) \\
17\end{array}$ \\
\hline$B / 1$ & $\begin{array}{l}20920 \\
(8917) \\
29\end{array}$ & $\begin{array}{l}46.5 \\
(15.0) \\
28\end{array}$ & $\begin{array}{l}35.8 \\
(6.3) \\
27\end{array}$ & $\begin{array}{l}1856.4 \\
(813.5) \\
11\end{array}$ \\
\hline $\mathrm{B} / 2$ & $\begin{array}{l}17661 \\
(6969) \\
12\end{array}$ & $\begin{array}{l}29.6 \\
(16.1\} \\
12\end{array}$ & $\begin{array}{l}38.2 \\
(4.8) \\
12\end{array}$ & $\begin{array}{l}1075.0 \\
(533.5) \\
3\end{array}$ \\
\hline$B / 3$ & $\begin{array}{l}20651 \\
(10173) \\
21\end{array}$ & $\begin{array}{l}16.8 \\
(3.6) \\
15\end{array}$ & $\begin{array}{l}36.6 \\
(6.6) \\
22\end{array}$ & $\begin{array}{l}1668.3 \\
(860.0) \\
3\end{array}$ \\
\hline C & $\begin{array}{l}3543 \\
(3711) \\
12\end{array}$ & $\begin{array}{l}11.2 \\
(1.5\} \\
12\end{array}$ & $\begin{array}{l}42.1 \\
(3.6) \\
12\end{array}$ & NR \\
\hline$D$ & $\begin{array}{l}7158 \\
(6277) \\
12\end{array}$ & $\begin{array}{l}8.5 \\
(1.1) \\
12\end{array}$ & $\begin{array}{l}44.9 \\
(5.9) \\
12\end{array}$ & NR \\
\hline
\end{tabular}


with high plasma creatine kinase that were probably lower than the correct values. Liver vitamin $E$ levels were established for Sites A and B (Table 2). The lowest levels were seen in groups with the highest percentage of pancreas disease $(\mathrm{A} / 2$ and $\mathrm{A} / 3)$. The populations with the lowest liver vitamin $E$ levels also had the highest level of skeletal muscle pathology but this correlation did not hold for cardiac pathology. Plasma lactate levels in the good condition fish (Groups 1 and 3) from Sites A and B showed significant elevation ( $p<$ 0.05 to 0.001 ) when compared to Sites $C$ and D, indicating the accumulation of lactic acid in the blood of these good condition fish, consistent with the muscle damage observed in the histology. Haematocrits in all clinically sick fish, i.e. $A / 1, A / 2, B / 1$ and $B / 2$, showed a reduction compared to Sites C and D ( $p<0.05$ to 0.001$)$, whereas the apparently healthy fish had no significant change. It should be noted that only Group A/2, affected with chronic pancreas disease, had any decrease in haematocrit bordering on a clinical anaemic state.

\section{DISCUSSION}

The histological findings in the heart and skeletal muscle are similar to changes observed in Atlantic salmon affected by pancreas disease in Scotland as reported by Ferguson et al. (1986b). The authors reported 'a good correlation between the presence of heart and pancreatic changes and they developed concurrently'. In the case studies reported here this was the finding in some samples, but the correlation was not complete in that cardiac pathology could be present in the absence of clinical or histopathological evidence of pancreas disease, as in the case of Site D. Skeletal muscle pathology however was only observed at sites with pancreas disease. Furthermore pancreas disease could be present without either cardiac pathology or skeletal muscle pathology. This last observation is consistent with the findings of McVicar (1987) who reported that cardiac and skeletal muscle changes were an inconsistent finding on Scottish pancreas disease affected farms. The prevalence of severe muscle degeneration in the apparently healthy fish, in this study, appears to be greater than that reported by Ferguson et al. (1986b). This may explain the low mortalities reported in the Scottish experience, compared to the stock losses at the present Sites A and B, which represented more than $50 \%$ of the post-smolts.

The correlation with liver vitamin E levels and the presence of pancreas disease showed a similar pattern to that described by Ferguson et al. (1986a) for fish affected with PD. Ferguson et al. (1986a) proposed that vitamin $\mathrm{E}$ deficiency could be either the cause of $\mathrm{PD}$ or a consequence of it. Their suggestion of a possible causal relationship was based on the known aetiological role of vitamin $\mathrm{E}$ and selenium deficiency in pancreatic atrophy in chicks (Thompson \& Scott 1970). Alternatively, absorption of vitamin $\mathrm{E}$ is dependent on a functional pancreas in that pancreatic lipase is a prerequisite for the formation of free fatty acids and monoglycerides which are essential components of the micelles within which vitamin $\mathrm{E}$ is absorbed. Thus, in the absence of lipase, malabsorption and consequent tissue depletion of vitamin $E$ would ensue. While the role of high versus low vitamin $\mathrm{E}$ diets in relation to the onset of PD was not examined in the present study, all affected fish were consuming high dietary levels of vitamin $\mathrm{E}\left(500 \mathrm{mg} \mathrm{kg}^{-1}\right)$ for 2 to 3 mo before the onset of the disease. This would suggest that PD cannot be prevented by such high dietary vitamin $\mathrm{E}$ levels. This agrees with the work of Bell et al. (1987) who considered that low vitamin $E$ in $P D$-affected salmon was a consequence rather than the cause of the disease. Knowledge on the relationship between PD and vitamin $\mathrm{E}$ has recently been expanded by experimental infection and feeding trials (Raynard et al. 1991) which showed that there is an increased susceptibility to pancreas disease with vitamin $\mathrm{E}$ deficiency. Of additional note in this study is that at Site A, where fish had the lowest liver vitamin $E$ levels, there was the greatest proportion of fish showing skeletal pathology, and moreover their lesions were more severe.

The findings of this study indicate that skeletal myopathy is highly significant in the aetiology of SDS. The actual proportion of fish with muscle pathology may have been greater than that recorded (Fig. 3), as only a limited number of muscle groups were examined. Furthermore lesions were often localised and focal, and may well have been overlooked in many fish. Cardiac pathology was observed at all 4 sites. However, in light of the fact that the highest percentages of cardiac lesions were in the populations that were not experiencing the mortalities, it was concluded that cardiac pathology may not be significant in SDS in Ireland. This would tend to distinguish SDS from the more severe cardiomyopathy reported by Ferguson et al. (1990) in Norwegian farmed salmon, which also differed in that the skeletal muscle pathology of the Norwegian fish was 'notably limited'.

Myopathy in terrestrial species due to vitamin E and selenium deficiencies is well documented and often occurs in animals which undergo a sudden increase in muscular activity following a period of inactivity and poor nutrition (Anderson et al. 1977). Myodegeneration has been demonstrated in Atlantic salmon fed an experimental diet deficient in vitamin $\mathrm{E}$ and selenium (Poston et al. 1976). The myopathy observed in SDS fish is degenerative and bilateral in samples examined, consistent with a nutritional cause. We cannot say that 


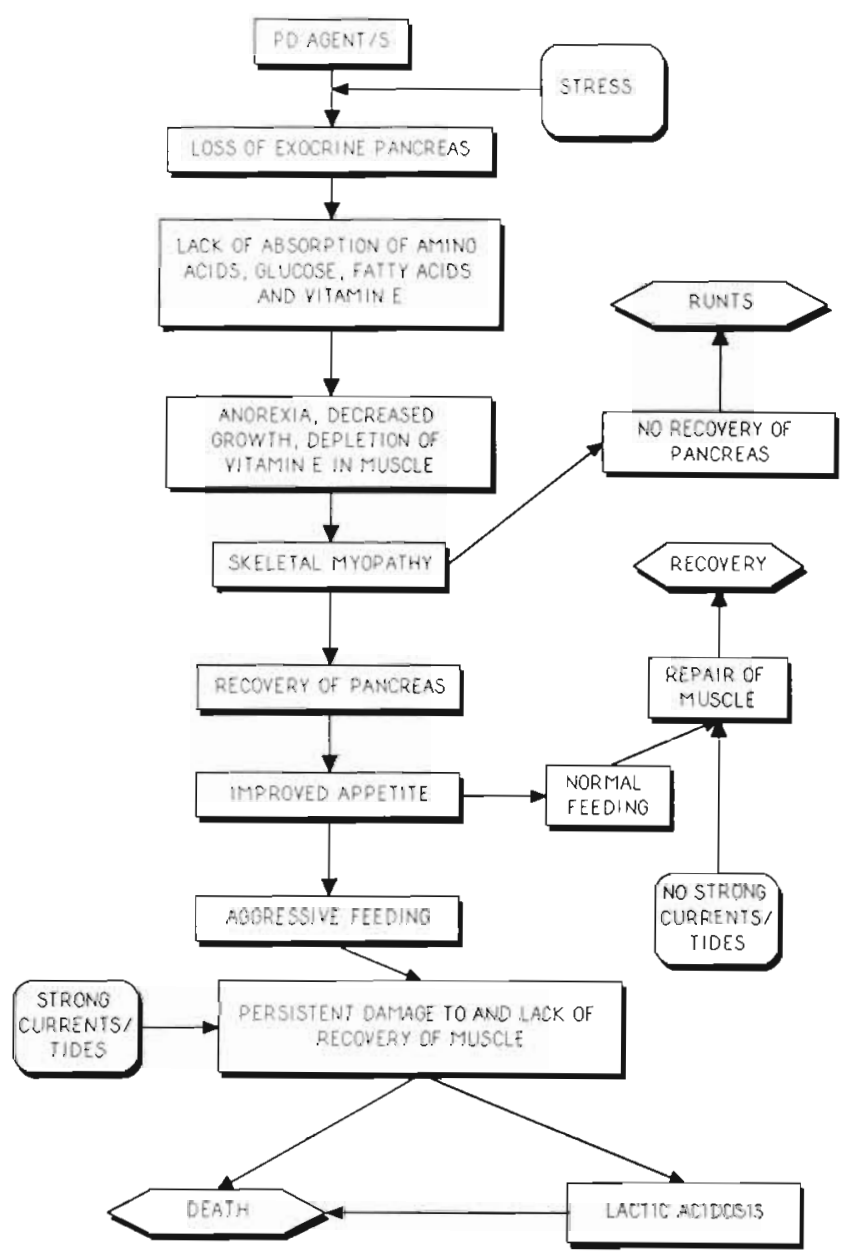

Fig. 6. A model proposing the most likely sequence of events leading to SDS

the SDS fish were vitamin $E$ deficient at the time of death because their lowest liver vitamin $E$ levels $\left(201.9 \mathrm{\mu g} \mathrm{g}^{-1}\right)$ were not as low as those found by Ferguson et al. (1986a) in PD-affected fish (20.8 to $64.7 \mu \mathrm{g}$ $\mathrm{g}^{-1}$ ). However the values found in the current study followed intake of dietary vitamin $E$ levels of up to $1500 \mathrm{mg} \mathrm{kg}^{-1}$ for 2 to 3 wk after the PD outbreaks. The initial muscle damage probably occurred several weeks earlier when the fish were suffering from anorexia and when it is likely that tissue vitamin $E$ levels were much lower. With vitamin E having become depleted at that time, the muscle damage would have been initiated. This damaged muscle would have been more susceptible to the vigorous and aggressive feeding behaviour observed during recovery from pancreas disease. This energetic, sustained use of muscles may be the factor which triggered the rapid increase in mortalities. Although we have not yet carried out histochemical examination of affected muscles, it has been widely reported in other species that Type 1 (oxidative) muscle fibres are pre- ferentially destroyed during vitamin E deficiency, as reported by Ruth \& Van Fleet (1974) in pigs and Kennedy (1985) in cattle. It is likely that a similar situation occurs in saimon, since in this study the highest incidence of myopathy was found in red muscles, i.e. those which have a high proportion of Type 1, fatigue-resistant fibres. When Type 1 fibres are destroyed, then the remaining Type 2 fibres, which are glycolytic and capable of only short bursts of energy, will be more susceptible to overuse, with a resulting buildup of lactic acid in the muscle fibres. We propose that overuse of the remaining healthy functional muscle fibres rapidly leads to a state of exhaustion. As a consequence, the damaged fibres will undergo more extreme damage and possibly cell rupture.

The acidosis resulting from the muscle degeneration and accumulation of lactic acid in the blood would reduce the availability of oxygen since haemoglobin would have a much reduced capacity to bind and carry oxygen, as observed by Root (1931), leading to anoxia. Death could therefore be a result either of non-function of essential muscles in, for example, the muscles effecting gill function, or of the anoxia resulting from lactic acidosis, or of a combination of both.

The 2 affected sites ( $A$ and $B$ ) both had greater exposure to wind and wave action than Sites C and D and are also subject to strong tidal currents. Post-smolts at these sites would therefore have to use their red muscle groups constantly as these are used in the aerobic swimming actions necessary to maintain body position in the water column.

In summary the most likely aetiology for the 'sudden death syndrome' may be that of muscle exhaustion and damage leading to failure of normal swimming and respiratory functions combined with blood acidosis and hence further anoxia leading to death. Based on these conclusions a model is proposed to define the most likely sequence of events leading to SDS (Fig. 6).

Control of the development of this syndrome will require control of the putative $\mathrm{PD}$ agent, and husbandry methods which will reduce the overall stress on the stocks. Fallowing sites, decreasing stocking densities and the use of the more sheltered, lower current sites should all have a beneficial effect. It may also be possible to reduce the likelihood of the initial peroxidative damage to muscle fibres by increasing further the antioxidant status of tissues, through reducing peroxidative substrates in the diet prior to and during a PD outbreak. All of these areas demand further investigation and research.

Acknowledgements. The assistance of $\mathrm{Mr} \mathrm{T}$ Buckley, Irish Equine Centre, Kildare, Ireland, Dr S. Kennedy, Veterinary Research Labs, Stormont, Belfast, Northern Ireland and Dr B. Roy, Dunstaffnage Marine Lab., Oban, Scotland in the analy- 
sis of tissue and blood chemistry was greatly appreciated. The virological screening performed by the Fisheries Research Centre, Dublin, Ireland and the Institute of Aquaculture, Stirling, Scotland is gratefully acknowledged. The assistance of Ms M. Ruttledge in histological preparation was also much appreciated.

\section{LITERATURE CITED}

Anderson, P. H., Bradley, R., Berrett, S., Patterson, D. S. P. (1977). The sequence of myodegeneration in nutritional myopathy in the older calf. Br. vet. J. 133: 160-165

Austin, B., Embley, T. M., Goodfellow, M. (1983). Selective isolation of Renibacterium salmoninarum. FEMS Microbiol. Lett. 17: 111-114

Bell, J. G., McVicar, A. H., Cowey, C. B. (1987). Pyruvate kinase isoenzymes in farmed Atlantic salmon (Salmo salar): pyruvate kinase and antioxidant parametrs in pancreas disease. Aquaculture 66: 33-41

Ferguson, H. W., Poppe, T., Speare, D. J. (1990). Cardiomyopathy in farmed Norwegian salmon. Dis. aquat. Org. 8: 225-231

Ferguson, H. W., Rice, D. A., Lynas, J. K. (1986a). Clinical pathology of myodegeneration (pancreas disease) in Atlantic salmon (Salmo salar). Vet. Rec. 119: 297-299

Ferguson, H. W., Roberts, R. J., Richards, R. H., Collins, R. O., Rice, D. A. (1986b). Severe degenerative cardiomyopathy associated with pancreas disease in Atlantic salmon, Salmo salar L. J. Fish Dis. 20: 95-98

Kennedy, S. (1985). Pathology of experimentally induced nu-

Responsible Subject Editor: G. Peters, Hamburg, Germany tritional degenerative myopathy in ruminant cattle. Ph.D. thesis, Queens University, Belfast

McMurray, C. H., Blanchflower, W J., Rice, D. A. (1980) Influence of extraction techniques on determination of $\alpha$ tocopherol in animal feeding stuffs. J. Ass. off. Anal. Chem. 63: 1258-1261

McVicar, A. H. (1987). Pancreas disease of farmed Atlantic salmon, Salmo salar, in Scotland: epidemiology and early pathology. Aquaculture $67 \cdot 71-78$

Munro, A. L. S., Ellis, A. E., McVicar, A. H., Mclay, H. A., Needham, E. A. (1984). An exocrine pancreas disease of farmed Atlantic salmon in Scotland. Helgoländer Meeresunters. 37: 571-586

Poston, H. A., Combs, G. F., Leibovitz, L. (1976). Vitamin E and selenium interrelations in the diet of Atlantic salmon (Salmo salar): gross, histological and biochemical deficiency signs. J. Nutr. 106: 892-904

Raynard, R. S., McVicar, A. H., Bell, J. G., Youngson, A., Knox, D., Fraser, C. O. (1991). Nutritional aspects of pancreas disease of Atlantic salmon: the effects of dietary vitamin $\mathrm{E}$ and polyunsaturated fatty acids. Comp. Biochem. Physiol. 98A (1): 125-131

Ruth, G. R., Van Fleet, J. F. (1974). Experimentally induced selenium-vitamin $E$ deficiency in growing swine: selective destruction of Type I skeletal muscle fibres. A.m. J. Vet. Res. 35: 237-244

Root, R. W. (1931). The respiratory function of the blood of marine fishes. Biol. Bull. mar. biol. Lab., Woods Hole 61: $427-456$

Thompson, J. N., Scott, M. L. (1970). Impaired lipid and vitamin $\mathrm{E}$ absorption related to atrophy of the pancreas in selenium deficient chicks. J. Nutr. 100: 797-809

Manuscript first received: March 13, 1991

Revised version accepted: August 14, 1991 